\title{
Framework for Lean Management in Industrial Services
}

\author{
Günther Schuh and Philipp Stüer \\ Philipp.Stueer@fir.rwth-aachen.de
}

\begin{abstract}
Industrial Service providers face the challenge of generating maximum customer value on the one hand and the efficient utilization of internal resources on the other hand. This challenge is further intensified by a worldwide growing market of industrial service providers. This paper presents a holistic approach for lean service management facing the named challenges. The framework is derived from various optimization projects in industrial service operations and supports companies to achieve excellent productivity within their service delivery.
\end{abstract}

Keywords: Key words: service management, lean services, service operations, customer value, service delivery processes.

\section{Introduction}

Within the next years industrial services will gain relevance not only in Germany [1]. The constantly growing number of jobs in Germanys' service sector is one indicator of this development (see Figure 1).

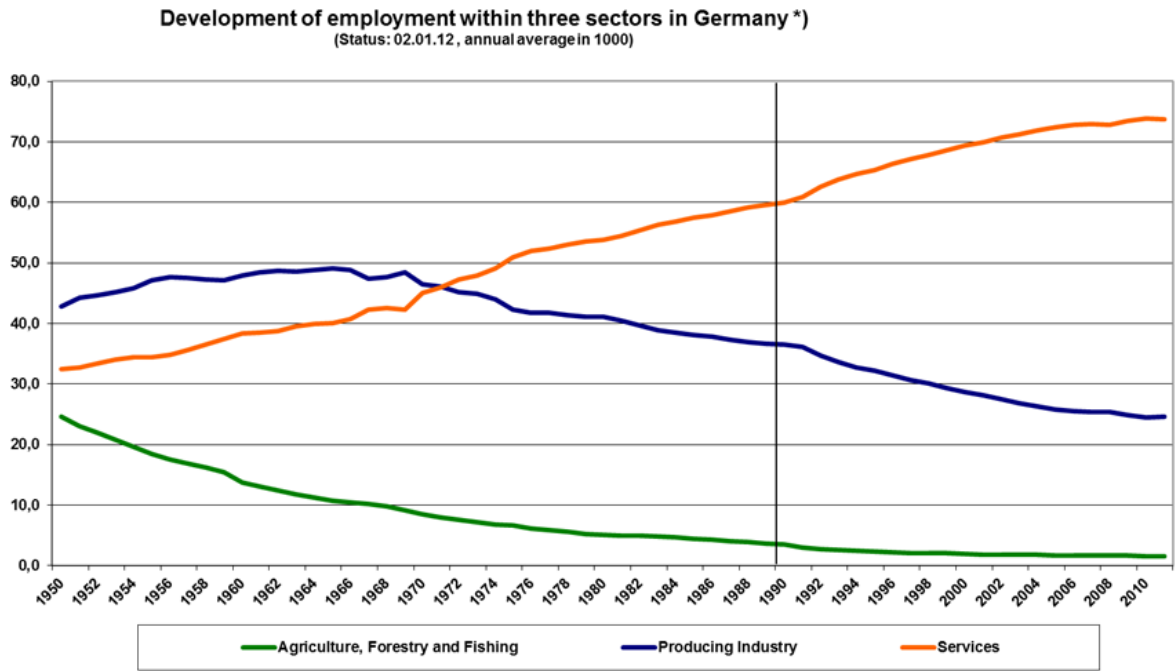

*) until 1990 western Germany including Western Berlin

Fig. 1. Development of employment within three sectors in Germany [2]

C. Emmanouilidis, M. Taisch, D. Kiritsis (Eds.): APMS 2012, Part II, IFIP AICT 398, pp. 392-398, 2013.

(c) IFIP International Federation for Information Processing 2013 
Growth of industrial services and increasing competition lead the focus of the scientific community towards service operations and approaches to increase productivity in this field. Industrial service companies suffer from a lack of procedures for increasing productivity and ensuring profitability. The question is how to efficiently and effectively design and operate service delivery processes. Adaptation of manufacturing proven management approaches would be one obvious way, which is intensively discussed within the scientific community. This paper describes a lean management framework for industrial services rooted in three significant service specific characteristics being described within the next chapter.

\section{Relevance and State of the Art}

As one of the most widespread techniques Lean Management has already been successfully transferred from manufacturing to adjacent fields like administration [3] and innovation [4], [5]. That Lean Management in its original form cannot directly be applied in the service context has already been stated by several publications [6], [7], [8]. Existing management approaches for industrial services either do not or only partly address service specific characteristics or they do not regard lean principles for industrial services until now [9].

Focusing industrial services three constitutive characteristics have to be regarded. First characteristic is the immateriality of services. Even if service delivery is often combined with a material good into an incentive system, the service part of the incentive system is immaterial. One exemplary process from industrial services is a repair process, in which spare parts are installed for ensuring technical availability of a machine or component. Experience and professionalism of the service staff together with high quality spare parts build an incentive system for the owner of the manufacturing plant as the customer.

Second constitutive characteristic is the integration of the external factor. As direct interaction between service provider and service customer or service object is required in industrial services [10]. Machines, components or a material good are also examples for the external factor.

The third characteristic refers to value as an original lean management principle. It says, that lean service delivery ether increases the customer value related to a material good, or the value contribution in a core value creation process (or value stream) of the customer.

\section{Objectives and Research Approach}

Regarding the named three characteristics a lean management approach for industrial services has to scope and analyze the customers' core processes before designing the service delivery processes with the purpose of adding customer value. Scope of lean service management also includes controlling, assessment and continuous improvement of running service delivery processes. Existing approaches for the description of 
a service lifecycle such as Raverdy 2008 [11] (see Figure 2) have also been influencing the creation of the core result of this paper.

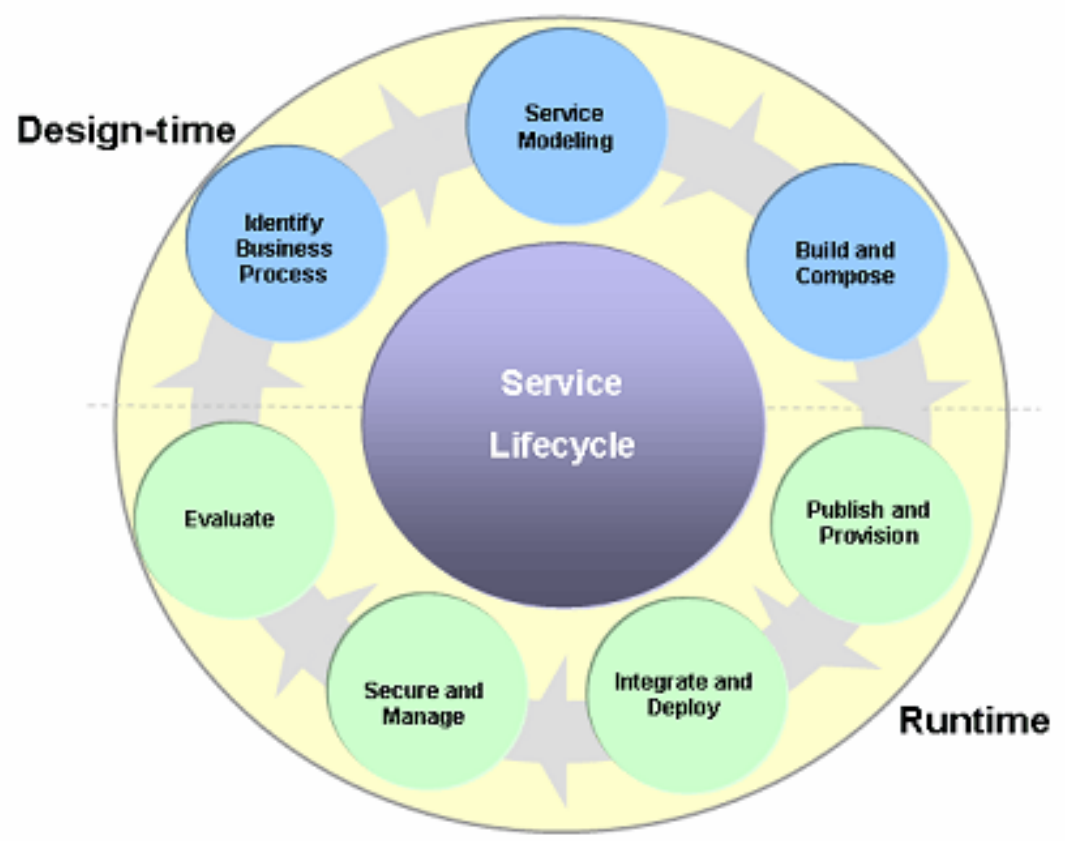

Fig. 2. Service lifecycle designed for mobile service platforms [11]

Within the following subchapters phases and principles of the framework for lean management in industrial services will be described. The following aspects have been extracted from several case study analyses. Keynote for this approach is the wastefree realization of customer value.

\section{Results: Framework for Lean Service Management}

The Lean Services Framework is divided in five phases. Each phase contains three principles for orientation towards excellence in lean service management. The phases and principles of the framework are positioned in a consecutive order. The framework begins with the phase defining strategic benefit and then leads to definition of service delivery processes and breadth of service offering. The last part of the framework focusses operational aspects of service management.

\subsection{Defining Strategic Benefit}

Before focusing service operations constraints for a waste-free realization of customer value have to be considered. Added value for the service customer can only be 
generated, when the service provider is capable to handle core processes of his customer complete or partly and with a higher productivity. Therefore Identification of Core Processes at the customer with potential for being delivered "as a service" has to be conducted.

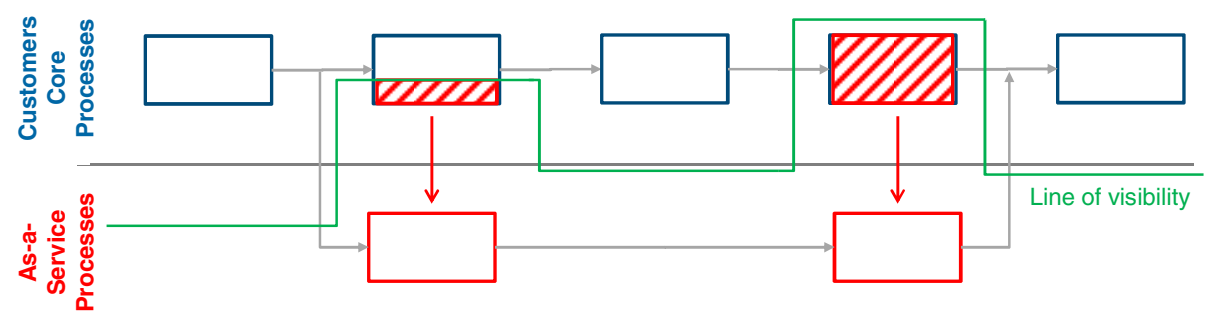

Fig. 3. Core processes at the customer and "as a service" processes delivered by the service provider

When core processes of the customer have been identified, the Strategic Positioning of Core Processes is the next principle within the framework. Core processes with high strategic importance for the customer bear lower chances for being offered to an external service provider. Strategic benefit for the customer is obvious, when service delivery strengthens him to achieve his goals with lower effort. For ensuring the realization of synergies within service delivery from the providers perspective Locating Priorities of Customers Goals is necessary. The phase Definition of Strategic Benefit is the root for high productive service delivery within the customers' core processes.

\subsection{Creating Service Value Stream}

Interaction between service customer and service provider significantly improves overall productivity of the core processes. Therefore the service provider has to describe a Definition of the Ideal Core Process including his contribution to value creation, meaning the added value for the customer. Result is transparency through Identification of Options for Added Value and Wastes within the customers' core processes.

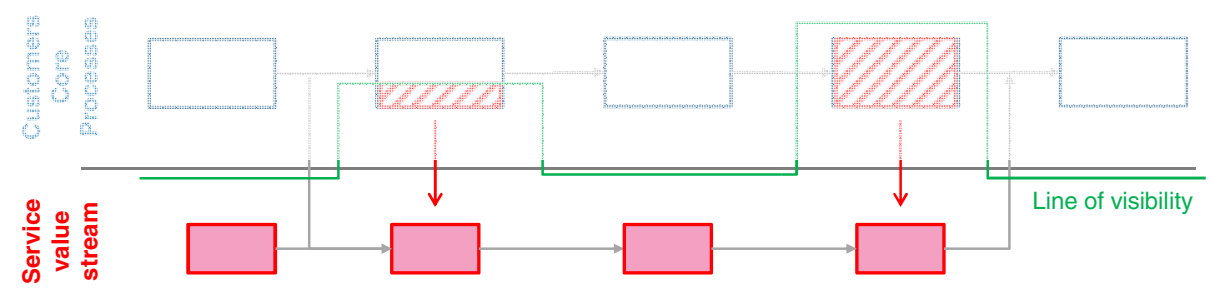

Fig. 4. Service value stream 
The service provider can identify options for added value and transparent wastes from comparing the ideal core process with the actual customers' core process. Building on the ideal core process the next principle of the framework is Definition of Service Types to be offered to the customer. Depending on quantity and possible combinations of options for added value, different types of services can be defined for the customer. Quantity and combination of service types directly impact the service delivery process and service productivity.

\subsection{Structuring Service Execution}

After focusing the service delivery process respectively the value stream, service execution needs to be structured. The principle Specification of Diversity and Range of Service Offers includes aspects of quantity structure and complexity. Capabilities of the service provider in terms of resources predominantly influence this phase of the lean service management framework. Service Configuration is the subsequent principle when structuring the service execution. Before considering characteristics of service operations, added value for the customer and the service provider has to be ensured through the subsequent principle Service Calculation. Objective is to quantify and validate the productivity advantage of the service-provider-performance towards the customers'.

\subsection{Simple Synchronization}

The phase Simple Synchronization is introduced by one of the core lean management principles rooted in the manufacturing context. To assure minimum waste through unnecessary resource disposition or wrong service configuration, decentralized control instruments through Implementing Pull Mechanisms are necessary. Synchronization of the customers' core processes with service delivery processes requires the Introduction of Tact. For synchronization with the customer the processes as well as resources have to be taken into account. The principle Introduction of Tact needs to receive further enhanced attention in terms of planning and scheduling, if several service providers are involved in one core customer process. After implementing pull mechanisms and introducing tact, Leveling Demand helps service providers to further increase resource efficiency. Decoupling point of service demand and point of service delivery as well as utilization of stackable activities supports balancing the workload of service staff under consideration of the principle Leveling Demand.

\subsection{Perfection}

Progress in striving towards perfection in lean industrial services management requires transparency of strategic and operative values. Selected specific Key Performance Indicators display the impact of improvement actions and customer satisfaction. Service Controlling allows an insight into the performance of service delivery which is related to the Simple Synchronization phase as well as the validation of Service Calculation aspects. The principle Service Controlling and KPI's is also closely 
related to the Structuring Service Performance phase of the framework. Steps on the path towards perfection can be described by a capability maturity model which is displayed in the principle Lean Performance Levels. Completing the framework for lean management in industrial services a Release Management describes milestones for service updates and detachment of obsolete service types and offers.

\section{Conclusion}

The framework for Lean Management in Industrial Services, which is described in this paper, sets apart from existing management approaches in this field. Industrial services underlie three main distinguishing characteristics towards manufacturing as the root of the classic five lean principles. These characteristics require a specific management approach for industrial services. Based on state of the art literature analysis, project work with leading providers of industrial services in Germany and the analysis of several case studies, this approach for Lean Management in Industrial Services was created. Customer value, the core processes of the customer and the lasting pursuit for productivity improvement have led the authors' research to the Framework for Lean Management in Industrial Services (see Figure 5). Together with the five phases "Defining Strategic Benefit", "Creating the Service Value Stream", "Structuring Service Execution", "Simple Synchronization" and "Perfection" 15 Principles help service companies to identify chances and implement Lean Management in their operational business.

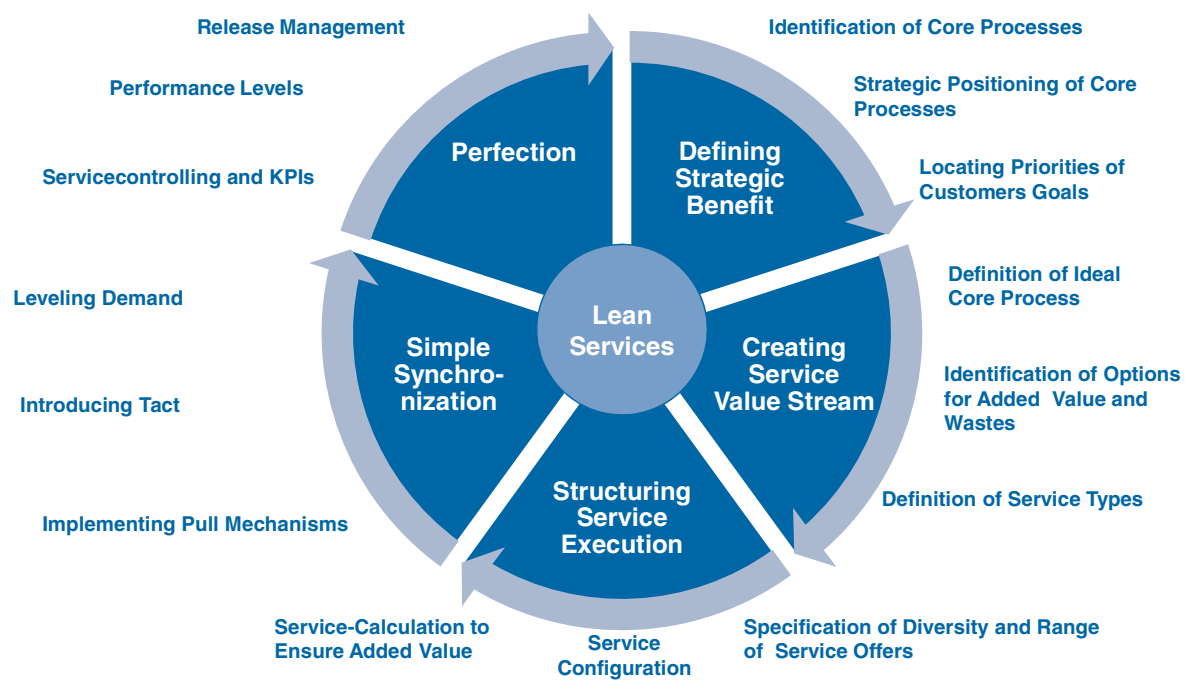

Fig. 5. Framework for Lean Management in Industrial Services 


\section{References}

1. Berger, R.: Studie Industrieservices Deutschland (2010)

2. Statistisches Bundesamt, B3-Presse- und Informationsservice (2012), https: / / www.destatis.de

3. Wiegand: Lean Administration (2007)

4. Lenders: Lean Innovation - Prinzipien und Methoden für Innovation ohne Verschwendung; Siemens Plm Connection 2010 (2010)

5. Schuh: Mit Lean Innovation zu mehr Erfolg (2007)

6. Bicheno: The Lean Toolbox for Service Systems (2008)

7. Womack/Jones: Lean Thinking (2004)

8. Åhlstrom: Lean Service Operation: translating lean production principles to service operations (2004)

9. Portioli-Staudacher: Lean Implementation in Service Companies (2010)

10. Corsten/Gössinger: Dienstleistungsmanagement (2007)

11. Raverdy: Whitepaper Service Lifecycle Management (2008) 